\title{
Conspecific preferences in prairie voles, Microtus ochrogaster, and meadow voles, M. pennsylvanicus
}

\author{
JOHN D. PIERCE, JR., BRUCE FERGUSON, and DONALD A. DEWSBURY \\ University of Florida, Gainesville, Florida
}

\begin{abstract}
Interactions between congeneric species in sympatry offer opportunities to study mating preferences for conspecifics, preferences that maintain premating reproductive isolation between species. Sixteen males and 16 females of two sympatric species, prairie voles (Microtus ochrogaster) and meadow voles (M. pennsylvanicus), were tested for conspecific as opposed to heterospecific preferences in an automated preference apparatus. The results indicated that male prairie and meadow voles displayed preferences for conspecifics when the females were in estrus, but showed no preference when females were in diestrus. Female prairie voles in both estrous and diestrous conditions likewise displayed a preference for conspecifics, whereas meadow vole females showed no such preference. These species differences may be related to social organization, for prairie voles are monogamous, pair-bonding, and contact-prone, whereas meadow voles, which are polygamous, display high intraspecific aggression during initial contact. Conspecific preferences can be considered as one factor that maintains existing isolation between the species.
\end{abstract}

Interactions between congeneric species in sympatry offer opportunities to study the factors that maintain premating reproductive isolation between those species. The discrimination of and mating preferences for conspecifics constitute one such factor. This study was designed to investigate conspecific preferences in two sympatric species of voles, prairie voles (Microtus ochrogaster) and meadow voles (M. pennsylvanicus).

For sympatric species, the ability to discriminate conspecifics from heterospecifics is important for such reasons as the selection of a mating partner and the exclusion of potential resource competitors. As one might expect, the species tested have generally shown a preference for conspecifics over members of closely related species. In two-choice preference tests, male preferences for female conspecifics have been demonstrated in several species of mice of the genus Peromyscus (Bradshaw, 1965; Moore, 1965; Smith, 1965). Murphy (1977) reported that females of three hamster species displayed preferences for conspecific males. Turkish hamsters, the species with the greatest sympatric overlap, showed the strongest conspecific preference (Murphy, 1977, 1978). Preferences for conspecific odors or avoidance of heterospecific odors have been noted for several vole species, including male Microtus californicus (Heske \& Repp, 1986), M. pennsylvanicus (McGuire \& Novak, 1987), M. agrestis, and Clethrionomys glareolus (de Jonge,

This research was supported by Grant BNS-8520318 from the National Science Foundation. The authors thank Stephen A. Taylor for helpful comments. Requests for reprints should be sent to Donald A. Dewsbury, Department of Psychology, University of Florida, Gainesville, FL 32611.
$1980,1983)$. Preferences in meadow voles are interesting in that postnatal experience may influence these preferences. Cross-fostered meadow voles have displayed preferences for prairie voles (the foster species) as adults, whereas in-fostered meadow voles have preferred conspecifics (McGuire \& Novak, 1987). Brown (1979) has reviewed further evidence for conspecific preferences in several taxa.

Prairie voles and meadow voles offer an opportunity to study conspecific preferences in two Microtus species. These species are sympatric in at least part of their range (Getz, 1962; Krebs, Keller, \& Tamarin, 1969), and interspecies interactions probably do occur between them (Zimmerman, 1965; but see Krebs, 1977). Various studies have indicated that prairie voles and meadow voles display high inter- and intraspecific aggression during staged encounters (Colvin, 1973; Getz, 1962; Miller, 1969). In general, high intrasexual aggression has been observed within meadow voles, and high intersexual aggression has been found between species. These subtle differences in individual behavior may be a factor in the actual matingsystem differences between these two species, with prairie voles generally displaying a monogamous mating system (Carter, Getz, \& Cohen-Parsons, 1986; Getz, Carter, \& Gavish, 1981; Getz \& Hoffman, 1986) and meadow voles generally polygamous (Madison, 1980a, 1980b).

The differences in intra- and interspecies aggression between prairie voles and meadow voles suggest that these species can discriminate conspecifics from heterospecifics. The objective of the present study was to determine if this discrimination results in a preference for conspecifics over heterospecifics, and also, if this preference is influenced by the reproductive state of the female (i.e., estrus or diestrus). 
Table 1

Visitation by Male Prairie Voles and Male Meadow Voles to Estrous and Diestrous Conspecific and Heterospecific Females

\begin{tabular}{|c|c|c|c|c|c|c|}
\hline \multirow[b]{2}{*}{ Male } & \multicolumn{3}{|c|}{$\begin{array}{l}\text { Duration of Visit } \\
\text { (in seconds) }\end{array}$} & \multicolumn{3}{|c|}{ Number of Visits } \\
\hline & Consp. & Heterosp. & $t$ & Consp. & Heterosp. & $t$ \\
\hline \multicolumn{7}{|c|}{ Estrous females } \\
\hline Prairie vole & 2189.8 & 476.9 & $4.11 \dagger$ & 15.5 & 10.6 & $2.29^{*}$ \\
\hline Meadow vole & 1440.9 & 488.7 & $4.05 \dagger$ & 29.8 & 26.2 & 0.94 \\
\hline \multicolumn{7}{|c|}{ Diestrous females } \\
\hline Prairie vole & 937.8 & 1210.7 & 0.60 & 25.0 & 34.8 & 1.12 \\
\hline Meadow vole & 896.3 & 1359.1 & 0.74 & 13.8 & 16.2 & 0.58 \\
\hline
\end{tabular}

Note-Consp. $=$ conspecific female. Heterosp. $=$ heterospecific female. ${ }^{*} p<.05$. $\dagger p<.01$.

\section{METHOD}

\section{Subjects}

The subjects were 16 male and 16 female prairie voles, Microtus ochrogaster, and 16 male and 16 female meadow voles, M. pennsylvanicus, born and maintained in the laboratory colony at the University of Florida. Prior to testing, the subjects were individually housed in $23 \times 19 \times 13 \mathrm{~cm}$ polycarbonate cages in homospecific colony rooms on a reversed 16:8-h light:dark photoperiod. Water and Purina rabbit chow were available ad lib. The males of both species were pretested for copulatory behavior prior to testing. The female prairie voles were sexually experienced at the time of testing; the female meadow voles were sexually inexperienced.

\section{Apparatus}

The choice tests were conducted in the automated preference apparatus described by Webster, Williams, Sawrey, and Dewsbury (1984). Briefly, this is a $44 \times 21.5 \times 20 \mathrm{~cm}$ Plexiglas chamber divided by two partitions into a $20 \times 20.5 \mathrm{~cm}$ central area and two smaller $10 \times 20 \mathrm{~cm}$ compartments, one at each end. The stimulus animals were confined in $8 \times 7 \times 8 \mathrm{~cm}$ stimulus boxes external to the two smaller compartments. Internal alleys through the partitions and smaller compartments allowed free access to the stimulus boxes by the subjects, with a double piece of hardware cloth separating the stimulus animals from the subjects. Thus, the subjects could approach and interact with each stimulus animal without actually making contact with that animal. For each experimental run, the stimulus animals were placed in the endboxes 10$15 \mathrm{~min}$ before testing, where they remained for the duration of the test. The subjects were introduced via a central startbox to begin testing. The numbers of visits and the total durations of visits were recorded automatically by photocells (see Webster et al., 1984).

\section{Procedure}

The procedure for all experimental trials involved the presentation of an unrestrained choice animal with two stimulus animals that were constrained in the stimulus endboxes. All subjects were given at least $1 \mathrm{~h}$ of habituation in the endboxes and central arena 1-2 weeks before testing and in the endboxes 10-15 min immediately before testing.

In Experiment 1, 16 sexually experienced male voles of each species were given two 1-h tests at least 2 weeks apart. In one test, the male subjects were presented with 2 diestrous females, 1 conspecific and 1 heterospecific. In the other test, the male subjects were presented with 2 estrous females, 1 conspecific and 1 heterospecific. The design was counterbalanced across conditions, with half of the males presented with diestrous females first and half of the males presented with estrous females first. The males from each experimental condition were given the reverse treatment the following session.

The females used as estrous stimulus animals were brought into behavioral receptivity by injections of $0.06 \mathrm{mg}$ of estradiol benzoate 3 days prior to testing and $0.6 \mathrm{mg}$ of progesterone $4-6 \mathrm{~h}$ before testing. All females had vaginal smears taken on the day of testing. Females whose smears indicated first-day estrus (defined as a virtual lack of leucocytes and a predominance of nonnucleated squamous cells) on the test day were used as the estrous subjects. Females that had not been hormoneinjected and that had predominately leucocytes with nucleated epithelial cells were used as the diestrous subjects.

In Experiment 2, 16 females of each species were tested in the automated choice apparatus in two conditions. In one test, the female subjects were presented with 2 constrained males, 1 conspecific and 1 heterospecific, when the female was in diestrus. In the other test, the female subjects were presented with 2 constrained males, 1 conspecific and 1 heterospecific, when the female was in estrus. The trials lasted $1 \mathrm{~h}$ and were counterbalanced across conditions, as in Experiment 1. The females from each experimental condition were given the reverse treatment 2-4 weeks after initial testing.

For all subjects, the total number and duration of visits to the central chamber and each endbox were recorded.

\section{RESULTS}

The results of Experiment 1 can be found in Table 1 . No conspecific preference was demonstrated by the males of either species when the females were in diestrus. Differences in frequency of visits and amount of visitation to conspecific and heterospecific diestrous females were not significant for either the prairie vole males or the meadow vole males. When the stimulus females were in the estrous condition, the males of both vole species showed a preference for the conspecific females. The prairie vole males visited the conspecific females significantly more often and for longer durations than they visited the heterospecific females. The meadow vole males visited the conspecific estrous females for significantly longer durations than they visited the heterospecific estrous females, although the numbers of visits to each female did not differ significantly.

The results of Experiment 2 are presented in Table 2. In both the estrous and the diestrous conditions, the prairie vole females showed both significantly greater numbers and longer durations of visits to conspecific than to heterospecific males. In contrast, the estrous and diestrous meadow vole females showed no significant differences

Table 2

Visitation by Estrous and Diestrous Prairie Vole and Meadow Vole Females to Conspecific and Heterospecific Males

\begin{tabular}{lcccccccc}
\hline & \multicolumn{2}{c}{ Duration of Visits (in seconds) } & & \multicolumn{3}{c}{ Number of Visits } \\
\cline { 2 - 4 } Female/Condition & Consp. & Heterosp. & \multicolumn{1}{c}{$t$} & & Consp. & Heterosp. & $t$ \\
\hline Prairie vole/Estrous & 1299.7 & 562.7 & $4.06 \dagger$ & & 28.6 & 19.8 & $2.59^{*}$ \\
Prairie vole/Diestrous & 1593.4 & 396.5 & $4.73 \dagger$ & & 57.1 & 31.7 & $4.23 \dagger$ \\
Meadow vole/Estrous & 1001.0 & 1316.9 & 0.47 & & 5.2 & 6.6 & 0.57 \\
Meadow vole/Diestrous & 825.3 & 752.1 & 0.15 & & 11.1 & 10.9 & 0.39 \\
\hline
\end{tabular}

Note-Consp. $=$ conspecific male. Heterosp. $=$ heterospecific male. ${ }^{*} p<.05 . \quad \dagger p<.01$. 
in either numbers of visits or amounts of visitation to conspecific as opposed to heterospecific males.

The disparate results between the prairie vole and meadow vole females in Experiment 2 led to a test of the hypothesis that the females of the different species may have spent unequal amounts of time in the central area. There was no significant difference in the durations of time spent in the center of the apparatus when the females were in either estrus [prairie vole $M=1,737.6 \mathrm{sec}$, meadow vole $M=1,282.1 \mathrm{sec} ; t(30)=0.28$, n.s.] or diestrus [prairie vole $M=1,610.1 \mathrm{sec}$, meadow vole $M$ $=1,597.6 \mathrm{sec}, t(30)=0.97$, n.s.].

\section{DISCUSSION}

When given a choice between conspecific and heterospecific females, the male prairie voles and male meadow voles displayed preferences for conspecifics when the females were in estrus, but they showed no preference when the females were in diestrus. The female prairie voles in both the estrous and the diestrous conditions likewise displayed preferences for conspecifics, whereas the female meadow voles showed no such preference.

The role of estrus in affecting male preference is interesting in light of the extensive research conducted on this topic. While male preferences for estrous conspecific females have been demonstrated in numerous species, it is not a universal phenomenon, and species vary greatly in the ease of demonstration of these preferences (Dewsbury, Ferguson, Hodges, \& Taylor, 1986; Taylor \& Dewsbury, 1988, in press). For species demonstrating a preference, there is evidence to suggest that ovarian-dependent changes in vaginal and urinary odors result in greater attractivity of estrous females to males (Brown, 1979), and such odors are believed to advertise the location of receptive females in the field. The present results fit well with this hypothesized role of estrous odors, for males of both species were attracted to estrous conspecific females. However, the absence of a displayed preference when females were in diestrus should not be taken as a failure of males to discriminate. In two-choice preference tests, "a lack of preference does not indicate inability to discriminate"' (Brown, 1979, p. 105).

The female visitation data from Experiment 2 are more difficult to interpret. There may be several reasons why the prairie vole and meadow vole females showed such differences in visiting. First, it is quite possible that since the prairie vole females had previous sexual experience, whereas the meadow vole females did not, this difference in experience led to different behaviors directed toward the stimulus males. While this possibility cannot be excluded, both the fact that all the females showed similar cornified, estrous vaginal smears and the absence of clear species differences in the amount of time spent away from either male (i.e., time spent in the central area) argue against this interpretation. Still, the work of McGuire and Novak (1987) has suggested that postnatal experience influences social preferences in meadow voles. It may be the case that copulatory experience likewise influences social preference. The meadow vole colony was eliminated shortly after the completion of these experiments, so there was no possibility for testing females matched for sexual experience.

Second, the species differences in visitation patterns may have been due to differential sampling by females of the two species. Whereas the prairie vole females displayed high numbers of visits to the stimulus males (see Table 2), the meadow vole females visited the males far less frequently. It is quite plausible that reduced levels of sampling on the part of the meadow vole females led to the absence of a preference. Related to this, Cranford and Derting (1983) have argued that meadow voles, when they are placed in small arenas, restrict their movements, show higher levels of avoidance, and are submissive. In larger arenas, meadow voles show higher frequencies of exploration, and they are more contact-oriented. The relatively small preference apparatus used in the present study may have led to the reduced levels of sampling on the part of the meadow vole females.
Finally, the different strategies of male visitation may reflect species differences toward conspecifics. Prairie voles can be characterized as contact-prone (Getz, 1962; Shapiro, 1987), pair-bonding, and monogamous, and they display low aggression during initial contact (Carter et al., 1986; Getz et al., 1981; Gray, Kenney, \& Dewsbury, 1977). In contrast, meadow vole females are primarily territorial (Madison, 1980a, $1980 \mathrm{~b}$ ) and polygamous, and they display high intraspecies aggression during initial contact (Getz, 1962; Gray et al., 1977). The greater tendency toward sociality in prairie voles may have influenced preference establishment in this species, whereas the aggressive tendencies in meadow voles may have hindered the establishment of preferences.

Interspecific encounters in the field between prairie voles and meadow voles are considered to be infrequent, although the species show extensive overlap in parts of their range (Krebs, 1977). The present results suggest that conspecific preferences may play a role in maintaining the separation between species.

\section{REFERENCES}

Bradshaw, W. N. (1965). Species discrimination in the Peromyscus leucopus group of mice. Texas Journal of Science, 17, 278-293.

Brown, R. E. (1979). Mammalian social odors: A critical review. In J. S. Rosenblatt, R. A. Hinde, C. Beer, and M. C. Bushnel (Eds.), Advances in the study of behavior (Vol. 10, pp. 103-162). New York: Academic Press.

Carter, C. S., Getz, L. L., \& Cohen-Parsons, M. (1986). Relationships between social organization and behavioral endocrinology in a monogamous mammal. Advances in the Study of Behavior, 16, 109-145.

Colvin, D. V. (1973). Agonistic behaviour in males of five species of voles Microtus. Animal Behaviour, 21, 471-480.

Cranford, J. A., \& Derting, T. L. (1983). Intra and interspecific behavior of Microtus pennsylvanicus and Microtus pinetorum. Behavioral Ecology \& Sociobiology, 13, 7-11.

DE JONGE, G. (1980). Response to con- and heterospecific male odours by the voles Microtus agrestis, M. arvalis and Clethrionomys glareolus with respect to competition for space. Behaviour, 73, 277-303.

DE JONGE, G. (1983). Aggression and group formation in the voles Microtus agrestis, $M$. arvalis and Clethrionomys glareolus in relation to intra- and interspecific competition. Behaviour, 84, 1-72.

Dewsbury, D. A., Ferguson, B., Hodges, A. W., \& TAYlor, S. A (1986). Tests of preferences of deer mice (Peromyscus maniculatus bairdi) for individuals and their odors as a function of sex and estrous condition. Journal of Comparative Psychology, 100, 117-127.

Gerz, L. L. (1962). Aggressive behavior of the meadow and prairie voles. Journal of Mammalogy, 43, 351-358.

GetZ, L. L., Carter, C. S., \& Gavish, L. (1981). The mating system of the prairie vole, Microtus ochrogaster: Field and laboratory evidence for pair-bonding. Behavioral Ecology \& Sociobiology, 8, 189-194.

Getz. L. L., \& Hoffman, J. E. (1986). Social organization in freeliving prairie voles, Microtus ochrogaster. Behavioral Ecology \& Sociobiology, 18, 275-282.

Gray, G. D., Kenney, A. M., \& Dewsbury, D. A. (1977). Adaptive significance of the copulatory behavior pattern of male meadow voles (Microtus pennsylvanicus) in relation to induction of ovulation and implantation in females. Journal of Comparative \& Physiological Psychology, 91, 1308-1319.

Heske, E. J., \& RePP, J. M. (1986). Laboratory and field evidence for the avoidance of California voles (Microtus californicus) by western harvest mice (Reithrodontomys megalotis). Canadian Journal of Zoology, 64, 1530-1534.

KREBS, C. J. (1977). Competition between Microtus pennsylvanicus and Microtus ochrogaster. American Midland Naturalist, 97, 42-49.

Krebs, C. J., Keller, B. L., \& TAMARIN, R. H. (1969). Microtus population biology: Demographic changes in fluctuating populations of $M$. ochrogaster and M. pennsylvanicus in Southern Indiana. Ecology, 50, 587-606.

Madison, D. M. (1980a). An integrated view of the social biology of Microtus pennsylvanicus. Biologist, 62, 20-33. 
Madison, D. M. (1980b). Space use and social structure in meadow voles, Microtus pennsylvanicus. Behavioral Ecology \& Sociobiology, 7, 65-71.

McGuire, B., \& NovaK, M. (1987). The effects of cross-fostering on the development of social preferences in meadow voles (Microtus pennsylvanicus). Behavioral \& Neural Biology, 47, 167-172.

MILLER, W. C. (1969). Ecological and ethological isolating mechanisms between Microtus pennsylvanicus and Microtus ochrogaster at Terre Haute, Indiana. American Midland Naturalist, 82, 140-148.

MOORE, R. E. (1965). Olfactory discrimination as an isolating mechanism between Peromyscus maniculatus and Peromyscus polionotus. American Midland Naturalist, 73, 85-100.

MURPHY, M. R. (1977). Intraspecific sexual preferences of female hamsters. Journal of Comparative \& Physiological Psychology, 91, 1337-1346

MURPHY, M. R. (1978). Oestrous Turkish hamsters display lordosis toward conspecific males but attack heterospecific males. Animal Behaviour, 26, 311-312.

SHAPIRo, L. E. (1987). Behavior, neuroanatomy, and social organization of two species of voles (Microtus ochrogaster and Microtus mon- tanus) (Doctoral dissertation, University of Florida, 1987). Disser tation Abstracts International, 48, 2495.

SMITH, M. H. (1965). Behavioral discrimination shown by allopatric and sympatric males of Peromyscus eremicus and Peromyscus californicus between females of the same two species. Evolution, 19, 430-435.

TAYLOR, S. A., \& DEWSBURY, D. A. (1988). Effects of experience and available cues on estrous versus diestrous preferences in male prairie voles, Microtus ochrogaster. Physiology \& Behavior, 42, 379-388.

TAYLOR, S. A., \& DEWSBURY, D. A. (in press). Male preferences for females of different reproductive conditions: A critical review. In D. MacDonald \& R. Brown (Eds.), Chemical signals in vertebrates $V$. Oxford: Oxford University Press.

Webster, D. G., Williams, D. C., Sawrey, D. K., \& Dewsbury, D. A. (1984). An automated apparatus for the assessment of social preferences in rodents. Behavior Research Methods, Instruments, \& Computers, 16, 3-6.

Zimmerman, E. G. (1965). A comparison of habitat and food of two species of Microtus. Journal of Mammalogy, 46, 605-612.

(Manuscript received November 12, 1988.) 